\title{
CONCENTRACIONES DE METALES EN SEDIMENTOS Y TEJIDOS MUSCULARES DE ALGUNOS PECES DE LA LAGUNA DE CASTILLERO, VENEZUELA.
}

\author{
Metals Concentration in Sediments and Muscular Tissues of Some \\ Fish from the Castillero Lagoon, Venezuela.
}

\author{
Aristide Márquez ${ }^{1}$, William Senior ${ }^{1}$, Gregorio Martínez ${ }^{1}$, Julián Castañeda ${ }^{1}$ y Ángel González ${ }^{2}$ \\ ${ }^{1}$ Departamento de Oceanografía, Instituto Oceanográfico de Venezuela, Universidad de Oriente, Núcleo de Sucre. Av. Universidad, \\ sector Cerro Colorado, Cumaná estado Sucre, Venezuela. E-mail: aristide@sucre.udo.edu.ve; aristd@cantv.net; aristd@gmail.com \\ 2 Instituto Limnológico, Universidad de Oriente, Núcleo de Bolívar.
}

\begin{abstract}
RESUMEN
Con el propósito de detectar alteraciones en el productivo ecosistema de la Laguna de Castillero (Caicara del Orinoco, municipio Cedeño del estado Bolívar, Venezuela), se presentan resultados de mediciones granulométricas y de las concentraciones de los metales pesados: $\mathrm{Fe}, \mathrm{Mn}, \mathrm{Zn}, \mathrm{Pb}$ y Co realizadas en junio 2001 sobre los sedimentos superficiales y del tejido muscular de varias especies autóctonas de peces (Plasgiosium squamossimos, Pigocentrus cariba, Pheudoplastyloma fasciatum, e Hypostomus spp realizadas en junio 2001. Utilizando técnica de espectrofotometría de absorción atómica con llama de aire acetileno, se determinó que, las concentraciones de metales más altas están representadas por manganeso, zinc y plomo. En la parte más interna de la laguna, el tipo de sedimento predominante es el lodo, constituyendo entre $30 \%$ y un $65 \%$ del material colectado por estación. Se encuentra, que esos niveles decrecen hacia la boca de la laguna, producto de la interacción de las corrientes de flujo/reflujo que lavan el sedimento y que se refleja en la mayor presencia de arena fina. El análisis estadístico de ANOVA muestra diferencias significativas entre las concentraciones de los metales en las estaciones, tipificadas por la presencia de promedios discrepantes. Los niveles promedios para los sedimentos superficiales de la zona son los siguientes: Fe $(3365,44 \pm 261,61), M n(132,17 \pm 25,46), \mathrm{Zn}(253,04 \pm$ $86,48), \mathrm{Pb}(17,02 \pm 2,21)$ y Co $(4,65 \pm 0,76) \mu \mathrm{g} / \mathrm{g}$. Similarmente, en el tejido muscular de los peces se cuantificaron las siguientes concentraciones: Fe entre $(31,26 \pm 0,06)$ y $(68,36 \pm 0,05)$; Mn entre $(2,02 \pm 0,05)$ y $(4,16 \pm 0,03) ; Z n$ entre $(19,09 \pm 0,01)$ y $(28,89 \pm 0,01)$; Pb entre $(0,38 \pm 0,01)$ y $(0,47 \pm 0,03) \mu \mathrm{g} / \mathrm{g}$. El
\end{abstract}

Recibido: 01 / 02 / 2006. Aceptado: 22 / 05 / 2007. análisis refleja una notable asociación entre los altos valores de concentraciones de metales y el tipo de sedimento, con un gradiente creciente hacia el sedimento tipo lodo. Se encuentran valores elevados en la concentración de $\mathrm{Pb}$ y $\mathrm{Zn}$, hecho atribuido al estrés que ejercen las actividades antropogénicas circundantes sobre la Laguna de Castillero. Se concluye que, en base al diagnóstico realizado, el ecosistema de la laguna se encuentra en evidente estado de deterioro con implicaciones que podrían afectar a las especies que habitan en ella y a su vez, las actividades económicas de las poblaciones que explotan los recursos bióticos de ese cuerpo de agua.

Palabras clave: Metales pesados, sedimentos, peces, contaminación, laguna de inundación.

\section{ABSTRACT}

To detected alterations in the productive ecosystem of the Castillero Lagoon (Caicara of the Orinoco, Cedeño Municipality, Bolivar State, Venezuela), results are presented for granulometric measurements and heavy metals concentrations: Fe, $\mathrm{Mn}, \mathrm{Zn}, \mathrm{Pb}$ and Co made in June 2001 on superface sediments and of the muscular tissue of several native species of fish (Plasgiosium squamossimos, Pigocentrus cariba, Pheudoplastyloma fasciatum, and Hypostomus spp. By using atomic absorption spectrophotometry with an air-acetylene flame, it was determined that the highest concentrations of metals are represented by manganese, zinc and lead. It was determined that the highest concentrations of metals are represented by manganese, zinc and lead. In the most internal part in the lagoon the type of predominant sediments is the mud, constituting among $30 \%$ and $65 \%$ of the material collected by station. Is that those levels fall toward the mouth of the lagoon, product of 
Concentraciones de metales en sedimentos y tejidos musculares de algunos peces de la Laguna de Castillero / Márquez, A. y col.

the interaction of the flow / reflux currents that washes the sediment and that is reflected in the biggest presence of fine sand. The statistical analysis of ANOVA shows significant differences among the concentrations of the metals in the stations, tipificated for the presence of different averages. The averages levels for the superficial sediments of the area are the following ones: Fe $(3365.44 \pm 261.61), \mathrm{Mn}(132.17 \pm 25.46)$, $\mathrm{Zn}(253.04 \pm 86.48), \mathrm{Pb}(17.02 \pm 2.21)$ y Co $(4.65 \pm 0.76) \mu \mathrm{g} / \mathrm{g}$. In similarly way, in the muscular tissue of the fish the following concentrations were quantified: Fe between (31.26 \pm 0.06$)$ and (68.36 \pm 0.05$)$; Mn between (2.02 \pm 0.05$)$ and (4.16 \pm 0.03$) ; \mathrm{Zn}$ between (19.09 \pm 0.01$)$ and $(28.89 \pm 0.01)$; Pb between $(0.38 \pm$ $0.01)$ and $(0.47 \pm 0.03) \mu \mathrm{g} / \mathrm{g}$. The analysis reflects a remarkable association between the high securities of concentrations of metals and the sediments type, with a growing gradient toward the sediments type mud. These are alarming values in concentration of $\mathrm{Pb}$ and $\mathrm{Zn}$, attributed to the stress that produces the anthropogenic activities surrounding the Lagoon of Castillero. It can be concluded that based on the diagnosis that the ecosystem of the lagoon is in evident state of deterioration with implications that could affect the species inhabit, and the economic activities of the population that exploit the resources biotiques of that body of water.

Key words: Heavy metals, sediments, fish, pollution, flood lagoon.

\section{INTRODUCCIÓN}

A menudo resulta difícil determinar si las medidas de concentración de metales en sedimentos representan condiciones de enriquecimiento natural o antropogénico, debido a que el contenido natural de los metales en el sedimento puede variar dependiendo de la mineralogía, contenido de materia orgánica y distribución del tamaño del grano [31, 36]. No obstante, actualmente la mayor concentración es de origen antropogénico $[9,33,63]$. El sedimento tiene una significación relevante en las investigaciones geoquímicas, ya que su caracterización puede ayudar a comprender ciertas condiciones de gran importancia, como son la concentración de contaminantes y su relación con las características generales y típicas de cada zona, principalmente en las áreas marino costeras, debido a que ellas tienen una interacción más dinámica con todos los procesos físicos, químicos y biológicos, que se desarrollan en el medio ambiente marino [11, 14, 51]. La diagénesis y acumulación de los metales en los sedimentos son factores que dependen grandemente de la condición redox del fondo y de la actividad microbiana, las cuales determinan las formas de asociación de los metales con la matriz de sedimento [2, 8, 13, 24, 62]. En la actualidad, la mayoría de los estudios sobre los sedimentos han sido orientados hacia las zonas de importancia ecológica, económica y social, que son de una u otra forma impactadas por las actividades humanas, tales como bahías, estuarios y lagunas costeras [14, 48, 68]. Los metales pesados son contaminantes y entran al sedimento desde los cuerpos de aguas produciéndose un aumento progresivo de sus concentraciones en el tiempo y posterior bioacumulación de organismos que forman parte de esos ecosistemas [51]. Por otra parte, los tejidos musculares de peces son analizados rutinariamente en los programas de monitoreos de contaminación en los ecosistemas por la tendencia que presentan a acumular contaminantes [39]. En Venezuela, los estudios sobre el contenido de metales en lagunas, han sido realizados mayoritariamente en sedimentos de zonas marino-costeras como en el caso de las lagunas de Tacarigua, Unare y Píritu, ubicadas en la región centro-oriental de Venezuela, en donde existe una actividad pesquera de relativa importancia [17].

En Venezuela, la Laguna de Castillero representa una porción de la zona de inundación del río Orinoco, principal río de Venezuela y considerado el tercero en importancia en América del Sur [64]. El Orinoco es considerado como un río tropical poco impactado, constituyendo uno de los sistemas fluviales de anegamiento más importantes del mundo [54]. En el margen derecho del río Orinoco, se distingue un complejo orillar localizado en su lecho, formado por aluviones recientes, afectado periódicamente por inundaciones, donde se han formado lagunas y planicies inundables, tal es el caso de la Laguna de Castillero. La sedimentación en las lagunas de inundación no es uniforme, debido a que intervienen factores bióticos, como la vegetación o abióticos (sustratos consolidados) que proceden como anclaje de los sedimentos [10].

En la actualidad, a nivel mundial se han incrementado estudios de contaminación en ambientes naturales como ríos y lagunas de inundación $[9,22]$, sin embargo, en la Laguna de Castillero hasta el presente, los trabajos relacionados con las concentraciones de metales pesados son escasos. En los sedimentos, sólo han sido reportadas concentraciones para hierro y cobre [22] y en las aguas se han realizado caracterización fisicoquímica [45]. La presente investigación se realizó con el propósito de cuantificar las concentraciones de hierro, manganeso, cinc, plomo y cobalto en los sedimentos y en los tejidos de varias especies autóctonas de peces de la Laguna de Castillero, con el propósito de verificar el posible grado de alteración, tanto en el sedimento como en los peces; debido a que estos ecosistemas son considerados uno de los más importantes en los trópicos $[10,23,25]$ y requieren conservación y administración cuidadosa, ya que ellos modulan la intensidad de las inundaciones de los ríos [40], sostienen importantes pesquerías locales [37], producen las tierras fértiles para la agricultura [23] y mantienen el hábitat una variedad de fauna, incluyendo las especies puestas en peligro de extinción [5], así como especies de potencial valor económico [38].

\section{MATERIALES Y MÉTODOS}

\section{Área de estudio}

La Laguna de Castillero (FIG. 1) se ubica al sureste de la población de Caicara del Orinoco (66 $06^{\prime} 17^{\prime \prime}$ W y $66^{\circ} 10^{\prime}$ 


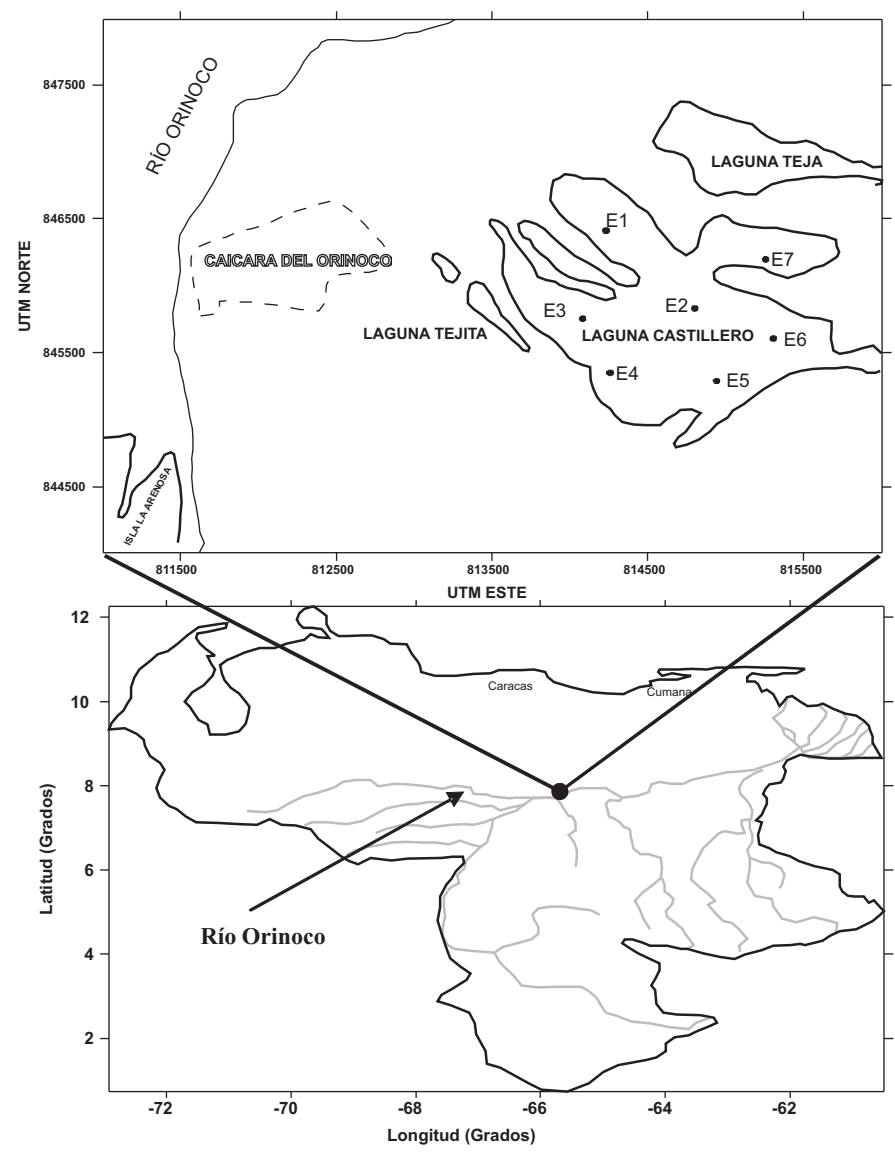

FIGURA 1. ÁREA DE ESTUDIO MOSTRANDO LA UBICACIÓN DE LOS SITIOS DE RECOLECCIÓN DE LOS SEDIMENTOS, EN LA LAGUNA DE CASTILLERO, ESTADO BOLÍVAR, VENEZUELA / STUDY AREA SHOWING THE LOCATION OF THE PLACES OF SAMPLING OF THE SEDIMENTS FROM THE CASTILLERO LAGOON, BOLÍVAR STATE, VENEZUELA.

05" N), municipio Cedeño del estado Bolívar en Venezuela. Ocupa una planicie de cota inferior a los $60 \mathrm{~m}$ sobre el nivel del mar y un área estimada de 140 ha. Los niveles de las aguas de la laguna se encuentran influenciados por una temporada de sequía que abarca los meses de noviembre hasta abril y uno de lluvia que se extiende desde mayo hasta octubre [44]. Los rebalses o planicies de inundación permanentes del Orinoco, cercanos a la población de Caicara del Orinoco y a la Laguna de Castillero se han utilizado como vertederos de aguas residuales Municipales, tal es el caso de la Laguna La Tejita, la cual tiene comunicación directa con la Laguna de Castillero. La misma recibía libremente aguas servidas de unas 430 familias y de desechos lubricantes provenientes de la planta eléctrica de la empresa ELEORIENTE desde el año 1988 hasta 1991. A partir de 1992 se suspendió la descarga cloacal, al construirse un colector de descarga que transportan las aguas residuales directamente al río Orinoco, de igual manera se construyó una estación eléctrica que eliminó la planta generadora de electricidad, suspendiéndose los vertidos de lubricantes hacia la laguna [12, 45].
Recolección del sedimento, peces y preparación y análisis de las muestras.

Con el propósito de tener la ubicación geográfica exacta de cada sitio, durante recolección de las muestras, las estaciones fueron georeferenciadas con un GPS Garmin 12XL (EUA), Siete (7) muestras de sedimentos superficiales fueron recolectadas en toda la extensión de la laguna (FIG. 1), durante el mes de junio del año 2001, utilizando una draga tipo Diez Laffon (EUA) de $0,02 \mathrm{~m}^{2}$ de área. Para evitar posible contaminación y alteración de los resultados, las muestras de sedimentos colectadas fueron colocadas en envases secos de poliestireno previamente lavados con $\mathrm{HNO}_{3}$ al $10 \%$ y abundante agua desionizada. Luego se transportaron al laboratorio del Instituto Limnológico de la Universidad de Oriente bajo refrigeración utilizando una cava con hielo. Las muestras se preservaron bajo congelación a $-20^{\circ} \mathrm{C}$, hasta la realización de los análisis.

Para el análisis granulométrico, los sedimentos fueron secados a $80^{\circ} \mathrm{C}$ en una estufa P SELECTA (EUA) y luego pasados a través de tamices de 4,$00 ; 2,00 ; 1,00 ; 0,85 ; 0,50 ; 0,25$ y 0,063 $\mathrm{mm}$. Para el análisis de los metales, las muestras fueron secadas a $80^{\circ} \mathrm{C}$ hasta obtener un peso constante, luego se pulverizaron y homogenizaron en un mortero de porcelana, almacenándose posteriormente en envases de polietileno herméticamente cerrados. $2 \mathrm{~g}$ de muestra por triplicado fueron una pesadas en una balanza analítica marca Denver Instrument M-10 (EUA) con precisión de $0,0001 \mathrm{~g}$, determinándose posteriormente los metales por digestión ácida con una mezcla de $\mathrm{HNO}_{3}: \mathrm{HCl}: \mathrm{HClO}_{4}$ en proporción 3:1:1 [28]. Las lecturas se hicieron por Espectrofotometría de Absorción Atómica (EUA) con llama de aire-acetileno y corrección de fondo de deuterio utilizando un espectrofotómetro Perkin Elmer, modelo 3110 (EUA), acoplado con un automuestreador Perkin Elmer AS-51 (EUA). Para evaluar la calidad analítica de las extracciones de los metales, se utilizó un patrón de sedimento estándar certificado por la Enviromental Resource Associates: Catálogo número 540, lote 237 (Priority Pollutn/CPL. Soil (EUA), TABLA II). Los porcentajes de extracción de metales en las muestras estudiadas fueron bastantes representativos, tal como lo demuestran desviaciones estándar bastante bajas para las 5 replicas analizadas y la comparación de los promedios obtenidos con el rango aceptable y el valor del patrón certificado.

Los análisis de metales en las especies dícticas fueron hechos en los tejidos musculares en un total de treinta ejemplares de cada uno de los géneros (Plasgiosium squamossimos (Curvinata), Pigocentrus cariba (Caribe), Pheudoplastyloma fasciatum, (Bagre rayado), Hypostomus spp. (Guaraguara), recolectadas en la misma fecha de la cosecha de los sedimentos. Los tejidos musculares son analizados rutinariamente en los programas de monitoreos en los ecosistemas por la tendencia que presentan a acumular contaminantes [39]. Para la captura de los peces se utilizó una red de ahorque de malla de luz de $7 \mathrm{~cm}$. Los peces capturados fueron trasladados bajo hielo hasta el laboratorio en donde se les realizaron cortes de los tejidos musculares por encima de la línea lateral y a nivel del inicio de la aleta dorsal. Para este propósito se utilizó un 
Concentraciones de metales en sedimentos y tejidos musculares de algunos peces de la Laguna de Castillero / Márquez, A. y col.

cuchillo limpio de acero inoxidable. Los tejidos fueron congelados a $-20^{\circ} \mathrm{C}$ y analizados siguiendo la metodología descritas en $[56,73]$.

Con los tejidos se realizaron 15 pool de 2 organismos para cada una de la especie respectiva y así se obtuvo la muestra final que fue analizada. Los tejidos fueron secados en una estufa $P$ SELECTA (EUA) a $80^{\circ} \mathrm{C}$, hasta obtener un peso constante, luego se pulverizaron y homogenizaron en un mortero de porcelana, almacenándose posteriormente en viales de vidrio herméticamente cerrados con tapas de Baquelita. $2 \mathrm{~g}$ de muestra seca por triplicado fueron tratados con ácido nítrico concentrado ultrapuro y analizados por Espectrofotometría de Absorción Atómica (EUA) con llama de aire-acetileno [32, 71] y corrección de fondo de deuterio, utilizando un equipo Perkin Elmer 3100 (EUA) acoplado con un automuestreador Perkin Elmer AS-51 (EUA). Los patrones de calibración y los blancos recibieron el mismo tratamiento. La eficiencia analítica del análisis de los tejidos fue chequeada usando un material estándar de referencia de Metilus edulis, BCR 278 (EUA), (TABLA I). La tasa de recuperación de las medidas del material de referencia estuvo dentro de un límite de confianza de 95\% del valor publicado para este material.

Toda el agua utilizada, tanto en la preparación de reactivos, curvas de calibración y blancos de reactivos fue agua desionizada altamente pura (agua calidad NANOPURE de conductividad de $18 \mathrm{M} \Omega / \mathrm{cm}$ ). Esto fue alcanzado con un sistema NANOPURE UV, Marca Barnstead (EUA). Al mismo tiempo, el material volumétrico de vidrio utilizado en el laboratorio fue de Clase A y los reactivos de Clase Analítica ultra pura.

Para validar los datos y determinar diferencias en las concentraciones de metales en las diferentes estaciones, se aplicó Análisis de Varianza de una vía empleando el Factor de Kruskal-Wallis con un nivel de significancia $P<0,05$ [57]. En el análisis estadístico de ANOVA se practicó la prueba de Cochran para chequear la homogeneidad de las varianzas [60], al mismo tiempo que se utilizó la prueba de rango múltiple de Duncan [57] a un nivel del $\mathrm{P}<0,05$ para identificar los
TABLA I

CONCENTRACIONES DE METALES MEDIDAS EN EL MATERIAL DE REFERENCIA DE TEJIDOS DE Mytilus edulis / HEAVY METALS CONCENTRATION FROM METALS MEASUREMENTS IN THE MATERIAL OF REFERENCE FROM THE TISSUES OF Mytilus edulis.

\begin{tabular}{ccr}
\hline $\begin{array}{c}\text { Metal } \\
(\mu \mathrm{g} / \mathrm{g})\end{array}$ & $\begin{array}{c}\text { Medidas } \\
\text { del BCR 278 }\end{array}$ & $\begin{array}{c}\text { Valores } \\
\text { certificados del BCR }\end{array}$ \\
\hline $\mathrm{Mn}$ & $7,69 \pm 0,23$ & $7,60 \pm 0,20$ \\
$\mathrm{Zn}$ & $83,1 \pm 1,70$ & $81,20 \pm 1,82$ \\
$\mathrm{~Pb}$ & $2,00 \pm 0,04$ & $1,99 \pm 0,19$ \\
\hline
\end{tabular}

grupos homogéneos. Para determinar asociaciones entre las estaciones se realizaron análisis estadísticos de conglomerados, empleando el método de mínima varianza de Ward's y la distancia métrica Euclidiana [57]. Los datos se analizaron con el paquete estadístico STATGRAPHICS Plus 4,1 (EUA). Para establecer la existencia o no de contaminación por metales pesados en la Laguna de Castillero, se realizaron comparaciones con los niveles propuestos [57].

\section{RESULTADOS Y DISCUSIÓN}

\section{Granulometría}

Los resultados representan los primeros registros granulométricos para la Laguna de Castillero (TABLA III). El análisis estadístico de conglomerados (FIG. 2) permitió establecer diferentes agrupaciones bien definidas entre las estaciones, lo cual pudo ser utilizado para dividir la Laguna de Castillero en zonas. Una zona conformada por las estaciones 1 y 6 localizadas en la zona oriental de la laguna, un segunda zona conformada por las estaciones 2; 4 y 5 ubicadas en la zona centrosur y una tercer conformada por las estación 3 y 7 situadas, la estación 3 en las adyacencias de la unión con la Laguna Teja y la estación 7 situada en la parte noreste de la Laguna de Castillero. Las sietes estaciones presentaron una granulometría bastante discrepantes (FIG. 3) constituidas en su mayoría

TABLA /I

PRECISIÓN DEL MÉTODO DE EXTRACCIÓN DE METALES PESADOS $(\mu \mathrm{g} / \mathrm{g})$ EN EL SEDIMENTO DE REFERENCIA/ THE PRECISION METHOD OF EXTRACTION THE TOTAL HEAVY METALS ( $\mu G / G)$ OF THE MATERIAL OF REFERENCE FROM THE SEDIMENT.

\begin{tabular}{cccccc}
\hline Muestra & $\mathrm{Fe}$ & $\mathrm{Zn}$ & $\mathrm{Mn}$ & $\mathrm{Co}$ & $\mathrm{Pb}$ \\
\hline 1 & 7981,36 & 87,27 & 110,8 & 81,73 & 70,87 \\
2 & 7996,69 & 87,78 & 111,96 & 80,59 & 69,12 \\
3 & 7991,32 & 87,49 & 110,61 & 81,43 & 69,58 \\
4 & 7990,86 & 88,12 & 113,51 & 81,58 & 71,47 \\
5 & 7993,86 & 86,98 & 111,39 & 81,36 & 72,00 \\
Prom & 7990,82 & 87,53 & 111,65 & 81,34 & 70,61 \\
DS & 5,78 & 0,44 & 1,16 & 0,44 & 1,22 \\
Rango Aceptado & $2890-12600$ & $67,90-108$ & $101-154$ & $70,50-106$ & $57,20-93$ \\
Valor Certificado & 7760 & 87,80 & 127,00 & 88,20 & 75,10 \\
\hline
\end{tabular}


TABLA III

CONCENTRACIONES PROMEDIOS DE METALES Fe, Mn, Pb, Zn y Co $(\mu \mathrm{g} / \mathrm{g})$ EN LOS SEDIMENTOS, Y GRANULOMETRÍA

(\%) EN LAGUNA DE CASTILLERO, VENEZUELA/ AVERAGE CONCENTRATIONS OF METAL Fe, Mn, Pb, Zn and Co ( $\mu \mathrm{g} / \mathrm{g})$ IN THE SEDIMENTS AND GRANULOMETRY (\%) FROM THE CASTILLERO LAGOON, VENEZUELA.

\begin{tabular}{ccccccccc}
\hline & $\mathrm{Pb}$ & $\mathrm{Mn}$ & $\mathrm{Fe}$ & $\mathrm{Zn}$ & $\mathrm{Co}$ & $\mathrm{AM}$ & $\mathrm{AF}$ & LODOS \\
\hline E1 & $11,46 \pm 0,03$ & $130,33 \pm 0,03$ & $3545,53 \pm 0,25$ & $25,81 \pm 0,04$ & $3,47 \pm 0,02$ & 25 & 40 & 35 \\
E2 & $22,84 \pm 0,04$ & $197,97 \pm 0,01$ & $3730,60 \pm 0,38$ & $166,87 \pm 0,09$ & $5,83 \pm 0,03$ & 16 & 22 & 62 \\
E3 & $21,4 \pm 0,03$ & $194,83 \pm 0,04$ & $3768,42 \pm 0,48$ & $686,60 \pm 0,05$ & $6,33 \pm 0,02$ & 10 & 25 & 65 \\
E4 & $21,38 \pm 0,01$ & $117,84 \pm 0,01$ & $3752,90 \pm 0,59$ & $289,87 \pm 0,02$ & $5,19 \pm 0,03$ & 12 & 32 & 56 \\
E5 & $20,27 \pm 0,02$ & $189,9 \pm 0,03$ & $3457,56 \pm 0,53$ & $243,41 \pm 0,03$ & $6,92 \pm 0,02$ & 11 & 37 & 52 \\
E6 & $13,89 \pm 0,02$ & $70,42 \pm 0,01$ & $3481,48 \pm 0,51$ & $112,41 \pm 0,05$ & $3,66 \pm 0,03$ & 25 & 43 & 32 \\
E7 & $7,91 \pm 0,12$ & $23,95 \pm 0,01$ & $1821,58 \pm 0,35$ & $346,34 \pm 0,05$ & $1,14 \pm 0,03$ & 34 & 36 & 30 \\
Max & $22,84 \pm 0,04$ & $197,97 \pm 0,01$ & $3768,42 \pm 0,48$ & $686,60 \pm 0,05$ & $6,92 \pm 0,02$ & 34 & 43 & 65 \\
Min & $7,91 \pm 0,12$ & $23,95 \pm 0,01$ & $1821,58 \pm 0,35$ & $112,41 \pm 0,05$ & $1,14 \pm 0,03$ & 10 & 22 & 30 \\
Prom & 17,02 & 132,17 & 3365,44 & 253,04 & 4,65 & & & \\
DS & 5,86 & 67,48 & 693,27 & 229,16 & 2,01 & & & \\
Error & 2,21 & 25,46 & 261,61 & 86,48 & 0,76 & & &
\end{tabular}

$\mathrm{E}=$ estación, $\mathrm{Pb}=$ plomo, $\mathrm{Mn}=$ manganeso, $\mathrm{Fe}=$ hierro, $\mathrm{Zn}=$ zinc, $\mathrm{Co}=$ cobalto, $\mathrm{AM}=$ arena media, $\mathrm{AF}=$ arena fina $, \mathrm{Max}=\mathrm{Máximo}, \mathrm{Min}=\mathrm{M}$ ínimo Prom $=$ promedio para la zona estudiada, DS $=$ desviación estándar, Error $=\mathrm{DS} / \mathrm{n}^{-1 / 2} ; \mathrm{n}=7=$ número de estaciones.

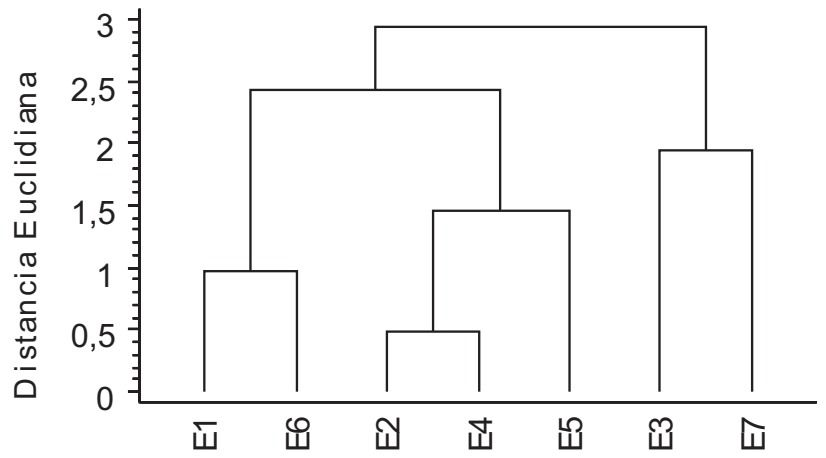

FIGURA 2. DENDOGRAMA DE SIMILITUD OBTENIDO CON EL ANÁLISIS DE CONGLOMERADO MOSTRANDO LA AGRUPACIÓN DE LAS ESTACIONES EN LA LAGUNA DE CASTILLERO. SE MUESTRAN TRES GRUPOS (E1, E6); (E2, E4, E5) Y (E3, E7)/ SIMILARITY DENDOGRAM OBTAINED BY WITH THE CONGLOMERATE ANALYSIS SHOWING THE GROUPS OF THE STATIONS IN CASTILLERO LAGOON. THREE GROUPS ARE SHOWN (E1, E6); (E2, E4, E5) AND (E3, E7).

por lodos (limos + arcilla) y arena fina. La heterogeneidad presentada por la distribución de las diferentes partículas, así como, la posición geográfica relativa de cada estación en los grupos conformados, hacen suponer que, dentro de la laguna existen factores que contribuyen de diferentes formas a la distribución de las partículas dentro de la laguna. Estos factores podrían estar influenciados por el sistema de corrientes y/o a la topografía de la laguna.

Los porcentajes de lodos variaron entre 30 y $65 \%$ determinándose los mayores porcentajes en las estaciones 2; 3 y 4 ubicadas en las adyacencias de la unión de las lagunas de Castillero y La Tejita, en el sector occidental. Los valores míni-

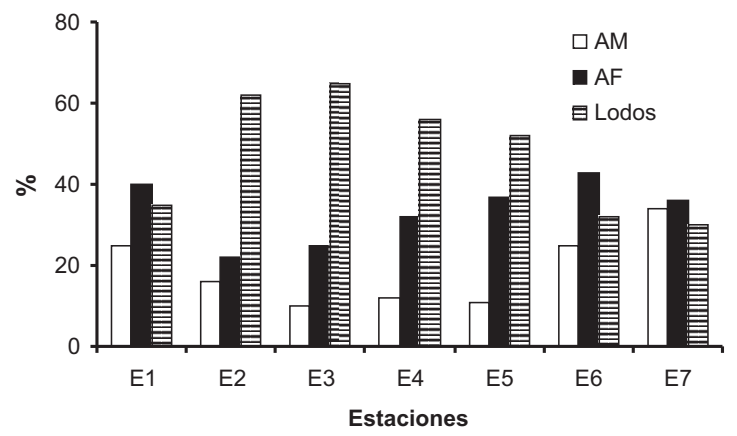

FIGURA 3. DISTRIBUCIÓN GRANULOMÉTRICAS DE LOS SEDIMENTOS SUPERFICIALES DE LA LAGUNA DE CASTILLERO, VENEZUELA (AM= ARENA MEDIA, AF= ARENA FINA)/ GRANULOMETRIC DISTRIBUTION OF THE SUPERFICIAL SEDIMENTS FROM THE CASTILLERO LAGOON, VENEZUELA (AM = HALF SAND, AF = FINE SAND).

mos fueron determinados en las estaciones 6 y 7 ubicadas en la parte este y sureste de la Laguna de Castillero. Los mayores porcentajes de lodos en las estaciones 2; 3 y 4 reflejan una sedimentación constante de las partículas pequeñas en la unión de las dos lagunas. Los porcentajes de arena fina a su vez, fueron bien homogéneos con porcentajes que oscilaron entre 22 y $40 \%$, mientras que los de arena media variaron entre 10 y $34 \%$.

\section{Metales pesados}

Las concentraciones de metales pesados presentaron una distribución no uniforme en toda la zona, esto se aprecia por la discrepancia en los valores de las desviaciones estándar, especialmente para el hierro (TABLA III). Se determinaron variaciones 
estadísticas significativas para las concentraciones de los metales en todas las estaciones (TABLA IV), observándose al mismo tiempo, buena correlación y asociación de todos los metales con el tamaño de la partícula especialmente con los lodos. El zinc por su parte exhibió mejor correlación con las arenas, especialmente con la arena tipo fina (TABLA V; FIG. 6). El orden de distribución encontrado en las concentraciones de los metales siguieron el orden $\mathrm{Fe}>\mathrm{Zn}>\mathrm{Mn}>\mathrm{Pb}>\mathrm{Co}$.

\section{Hierro}

Los valores de hierro (TABLA I y FIG. 4) fueron bastantes altos por ser un macro elemento. Se detectaron variaciones significativas de las concentraciones entre las estaciones (TABLA IV), al igual valores que oscilaron entre $1821,58 \mu \mathrm{g} / \mathrm{g}$ y 3768,42 $\mu \mathrm{g} / \mathrm{g}$ con promedio de $3768,42 \mu \mathrm{g} / \mathrm{g}$. Los niveles más elevados fueron apreciados en las estaciones 2; 3 y 5 ubicadas en la parte centro-occidental y sur de la Laguna de Castillero. Los niveles de hierro determinados duplican en magnitud a los valores reportados para los sedimentos de esta laguna [22]. Los autores antes señalados, reportaron promedios de hierro de 1488,2 $\mathrm{gg} / \mathrm{g}$ para los sedimentos de la Laguna de Castillero, así como, valores de 2137,9 $\mathrm{\mu g} / \mathrm{g}$ para los sedimentos del Orinoco Medio, específicamente en el sector Caicara del Orinoco. Por otra parte, para organismos vegetales que habitan en la Laguna de Castillero, como el caso de la planta de Bora (Eichhornia crassipes) se han reportado niveles de hierro que varían entre 2233,91 $\mu \mathrm{g} / \mathrm{g}$ y 1193, $25 \mu \mathrm{g} / \mathrm{g}$ [44]. Para las aguas de la Laguna de Castillero, por el mismo tiempo se han indicado niveles de hierro entre 0,62 $\mu \mathrm{g} / \mathrm{g}$ y $13,61 \mu \mathrm{g} / \mathrm{g}$ entre los meses de julio a noviembre, observándose en algunos casos que, entre el hierro y metales como el manganeso si existe una relación inversa en las concentraciones, la cual ha sido explicada como producto del nivel de inundación de la laguna [45]. Esta observación ha sugerido que la oxidación del hierro bivalente a forma trivalente puede ocurrir durante el período de aguas altas, mientras que en aguas bajas, por condiciones de anóxicas se produce una acumulación de hierro bivalente el cual se acumula en forma de de $\mathrm{Fe}_{3}\left(\mathrm{PO}_{4}\right)_{2}$.
TABLA IV

COMPARACIÓN (DUNCAN) DE LOS PORCENTAJES DE
PARTÍCULAS Y CONCENTRACIONES DE METALES
(P<0,05) EN LOS SEDIMENTOS DE LA LAGUNA DE
CASTILLERO/ COMPARISON (DUNCAN) OF THE PERCENTAGES
OF PARTICLES AND METAL CONCENTRATIONS (P<0.05) IN THE
SEDIMENTS FROM THE CASTILLERO LAGOON, VENEZUELA.

\begin{tabular}{|c|c|c|c|c|c|}
\hline \multicolumn{3}{|c|}{ AF } & \multicolumn{3}{|c|}{$\mathbf{A M}$} \\
\hline Estación & Prom & Grupos & Estación & Prom & Grupos \\
\hline E2 & 22,0 & $\mathrm{X}$ & E3 & 10,0 & $\mathrm{X}$ \\
\hline E3 & 25,0 & $\mathrm{X}$ & E5 & 11,0 & $\mathrm{X}$ \\
\hline E4 & 32,0 & $\mathrm{X}$ & E4 & 12,0 & $\mathrm{X}$ \\
\hline E7 & 36,0 & $\mathrm{X}$ & E2 & 16,0 & $\mathrm{X}$ \\
\hline E5 & 37,0 & $\mathrm{X}$ & E6 & 25,0 & $\mathrm{X}$ \\
\hline E1 & 40,0 & $\mathrm{X}$ & E1 & 25,0 & $\mathrm{X}$ \\
\hline E6 & 43,0 & $\mathrm{X}$ & E7 & 34,0 & $\mathrm{X}$ \\
\hline \multicolumn{3}{|c|}{ LODOS } & \multicolumn{3}{|c|}{$\mathrm{Fe}$} \\
\hline Estación & Prom & Grupos & Estación & Prom & Grupos \\
\hline E7 & 30,0 & $\mathrm{X}$ & E7 & 1821,23 & $\mathrm{X}$ \\
\hline E6 & 32,0 & $\mathrm{X}$ & E5 & 3457,02 & $\mathrm{X}$ \\
\hline E1 & 35,0 & $\mathrm{X}$ & E6 & 3481,97 & $\mathrm{X}$ \\
\hline E5 & 52,0 & $\mathrm{X}$ & E1 & 3545,28 & $\mathrm{X}$ \\
\hline E4 & 56,0 & $\mathrm{X}$ & E2 & 3730,23 & $\mathrm{X}$ \\
\hline E2 & 62,0 & $\mathrm{X}$ & E4 & 3753,31 & $\mathrm{X}$ \\
\hline E3 & 65,0 & $\mathrm{X}$ & E3 & 3768,9 & $\mathrm{X}$ \\
\hline \multicolumn{3}{|c|}{ Mn } & \multicolumn{3}{|c|}{$\mathrm{Zn}$} \\
\hline Estación & Prom & Grupos & Estación & Prom & Grupos \\
\hline E7 & 23,95 & $\mathrm{X}$ & E6 & 12,36 & $\mathrm{X}$ \\
\hline E6 & 70,42 & $\mathrm{X}$ & E1 & 25,77 & $\mathrm{X}$ \\
\hline E4 & 117,82 & $\mathrm{X}$ & E2 & 166,96 & $\mathrm{X}$ \\
\hline E1 & 130,30 & $\mathrm{X}$ & E5 & 243,37 & $\mathrm{X}$ \\
\hline E5 & 189,87 & $\mathrm{X}$ & E4 & 289,84 & $\mathrm{X}$ \\
\hline E3 & 194,86 & $\mathrm{X}$ & E7 & 346,29 & $\mathrm{X}$ \\
\hline E2 & 197,97 & $\mathrm{X}$ & E3 & 686,54 & $\mathrm{X}$ \\
\hline \multicolumn{3}{|c|}{$\mathbf{P b}$} & \multicolumn{3}{|c|}{ Co } \\
\hline Estación & Prom & Grupos & Estación & Prom & Grupos \\
\hline E7 & 8,02 & $\mathrm{X}$ & E7 & 1,11 & $\mathrm{X}$ \\
\hline E1 & 11,38 & $\mathrm{X}$ & E1 & 3,44 & $\mathrm{X}$ \\
\hline E6 & 13,88 & $X$ & E6 & 3,64 & $\mathrm{X}$ \\
\hline E5 & 20,24 & $\mathrm{X}$ & E4 & 5,15 & $\mathrm{X}$ \\
\hline E3 & 21,36 & $\mathrm{X}$ & E2 & 5,81 & $\mathrm{X}$ \\
\hline E4 & 21,36 & $\mathrm{X}$ & E3 & 6,31 & $\mathrm{X}$ \\
\hline E2 & 22,86 & $\mathrm{X}$ & E5 & 6,93 & $X$ \\
\hline
\end{tabular}

TABLA V

MATRIZ DE CORRELACIÓN DE PEARSON $(P<0,05)$ ENTRE METALES Y GRANULOMETRÍA EN LOS SEDIMENTOS SUPERFICIALES DE LA LAGUNA DE CASTILLERO, VENEZUELA/ PEARSON MATRIX CORRELATION (P<0.05) BETWEEN METALS AND GRANULOMETRY IN THE SUPERFICIAL SEDIMENTS OF THE LAGOON OF CASTILLERO, VENEZUELA.

\begin{tabular}{ccccccccc}
\hline & $\mathrm{Pb}$ & $\mathrm{Mn}$ & $\mathrm{Fe}$ & $\mathrm{Zn}$ & $\mathrm{Co}$ & $\mathrm{AM}$ & $\mathrm{AF}$ & LODOS \\
\hline $\mathrm{Pb}$ & 1,00 & & & & & & & \\
$\mathrm{Mn}$ & $0,83^{* *}$ & 1,00 & & & & & & \\
$\mathrm{Fe}$ & $0,78^{* *}$ & $0,75^{* *}$ & 1,00 & & & & & \\
$\mathrm{Zn}$ & 0,37 & 0,27 & $-0,06$ & 1,00 & & & & \\
$\mathrm{Co}$ & $0,94^{* *}$ & $0,90^{* *}$ & $0,78^{* *}$ & 0,38 & 1,00 & & & \\
$\mathrm{AM}$ & $-0,95^{* *}$ & $-0,85^{* *}$ & $-0,78^{* *}$ & $-0,42$ & $-0,99^{* *}$ & 1,00 & & \\
$\mathrm{AF}$ & $-0,70^{* *}$ & $-0,62^{*}$ & $-0,30$ & $0,60^{*}$ & $-0,54$ & 0,54 & 1,00 & 1,00 \\
LODOS & $0,95^{* *}$ & $0,84^{* *}$ & $0,64^{*}$ & 0,37 & $0,89^{* *}$ & $-0,90^{* *}$ & $-0,85^{* *}$ & \\
\hline
\end{tabular}

${ }^{*}=$ Significativo. ${ }^{* *}=$ Altamente significativo. 


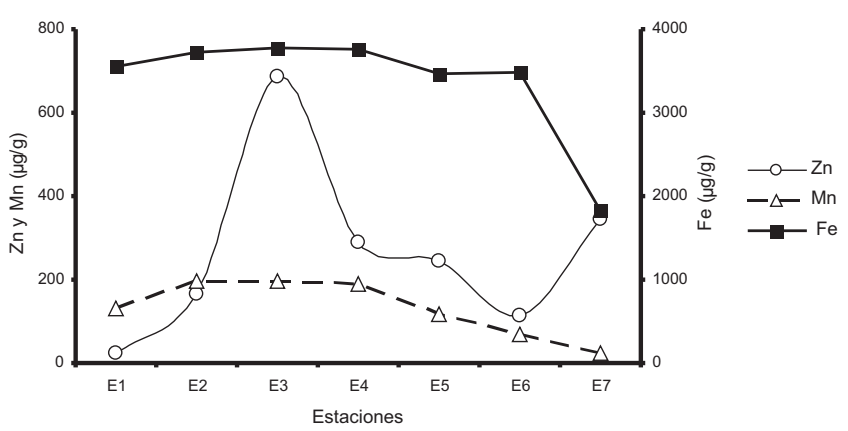

FIGURA 4. DISTRIBUCIÓN POR ESTACIONES DE LAS CONCENTRACIONES DE HIERRO, MANGANESO Y ZINC $(\mu \mathrm{g} / \mathrm{g})$ EN SEDIMENTOS SUPERFICIALES DE LA LAGUNA DE CASTILLERO, VENEZUELA./ DISTRIBUTION FOR STATIONS OF IRON, MANGANESE AND ZINC $(\mu \mathrm{g} / \mathrm{g})$ CONCENTRATIONS IN SUPERFICIAL SEDIMENTS FROM THE CASTILLERO LAGOON, VENEZUELA.

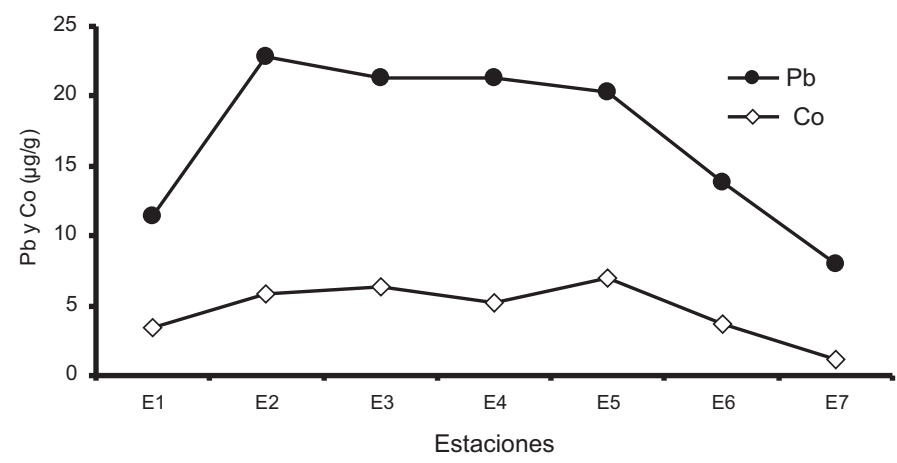

FIGURA. 5. DISTRIBUCIÓN DE LAS CONCENTRACIONES $(\mu \mathrm{g} / \mathrm{g})$ PLOMO Y COBALTO EN SEDIMENTOS SUPERFICIALES DE LA LAGUNA DE CASTILLERO, VENEZUELA/ DISTRIBUTION OF THE CONCENTRATIONS $(\mu \mathrm{g} / \mathrm{g})$ LEAD AND COBALT IN SUPERFICIAL SEDIMENTS FROM THE CASTILLERO LAGOON, VENEZUELA.

En los peces de la Laguna de Castillero por otra parte, las concentraciones de hierro oscilaron entre $28,80 \mu \mathrm{g} / \mathrm{g}$ para Hypostomus spp y $68,36 \mu \mathrm{g} / \mathrm{g}$ para $P$. fasciatum. Valores intermedios de $31,26 \mu \mathrm{g} / \mathrm{g}$ y $64,35 \mu \mathrm{g} / \mathrm{g}$ fueron determinados para $P$. squamossimos y $P$. cariba, respectivamente. El hierro es vital para la formación de hemoglobina, sin embargo altas concentraciones en el ambiente no sólo pueden afectar de manera diferente el contenido de este metal en los tejidos de los peces juveniles y adultos principalmente, sino que también pueden afectar las larvas y aún al saco vitelino, tal como se ha demostrado para la especie Salmo trutta [3] Las concentraciones de hierro determinadas en esta investigación son inferiores a las reportadas [22] para la especie $P$. squamossimos, capturadas en la Laguna de Castillero $(413,90$ a $507,90 \mu \mathrm{g} / \mathrm{g})$ y en el canal principal del Orinoco Medio (88,90 $\mu \mathrm{g} / \mathrm{g}-467,30 \mu \mathrm{g} / \mathrm{g})$.

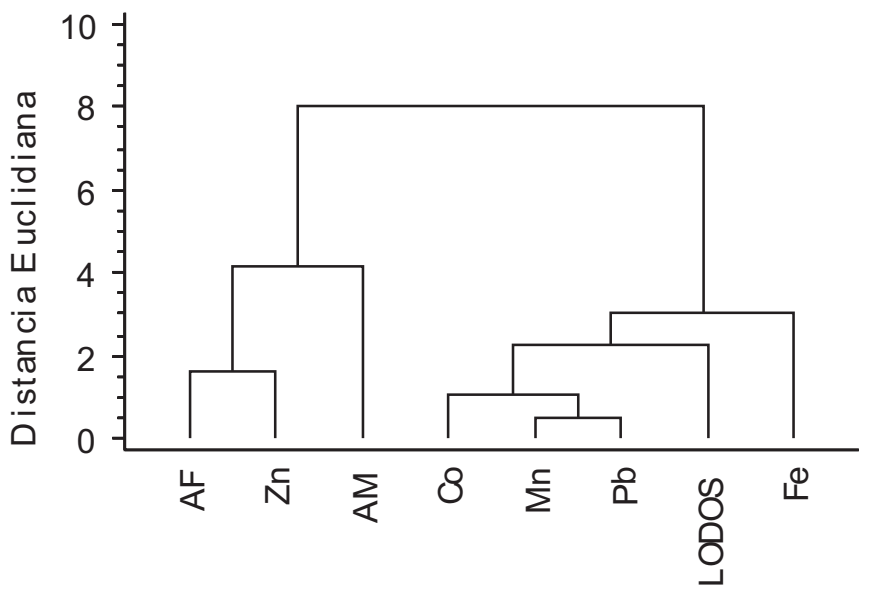

FIGURA 6. DENDOGRAMA DE SIMILITUD OBTENIDO CON EL ANÁLISIS DE CONGLOMERADO MOSTRANDO LA ASOCIACIÓN ENTRE LA GRANULOMETRÍA Y LAS CONCENTRACIONES DE METALES EN LAGUNA DE CASTILLERO, VENEZUELA./ SIMILARITY DENDOGRAM OBTAINED BY WITH THE CONGLOMERATE ANALYSIS SHOWING THE ASSOCIATION BETWEEN THE GRANULOMETRY AND THE METAL CONCENTRATIONS FROM THE CASTILLERO LAGOON, VENEZUELA.

El hierro se encuentra entre los metales esenciales para los seres vivos debido a que intervienen en una gran variedad de funciones biológicas y bioquímicas [4, 22], sin embargo, puede hacerse tóxico cuando se encuentra en altas concentraciones. Aunque los valores observados en esta investigación son un tanto superior a los reportados por González y col. [22], para los sedimentos de la Laguna de Castillero, las concentraciones no dan indicio de contaminación que altere la concentración de hierro en las especies estudiadas. El hierro distribuido por todo el mundo siendo el metal más abundante [21, 34].

En otros ecosistemas venezolanos, se han señalado promedios de hierro de 1,61\%; para los sedimentos de la cuenca Tuy-Cariaco [19], de 1,48\% para los sedimentos superficiales de la Laguna de Las Marites [52] y $5,2 \%$ en la Bahía de Barcelona [20]. Igualmente, valores de $1,56 \%$ de hierro han sido indicados para la Laguna de Unare, observándose que el hierro se encuentra en mayor proporción como forma de hierro residual [17]. En la Laguna Píritu los sedimentos presentan niveles de hierro cercanos a $2,66 \%$, de los cuales la mayor proporción se encuentra principalmente asociado a las fracciones materia orgánica y a los óxidos de hierro y manganeso [30]. Por encontrarse en grandes proporciones en la corteza terrestre, las concentraciones de hierro suelen incrementarse en los ambientes acuáticos durante los períodos de lluvia debido a la influencia de los ríos, los cuales constituyen una de las vías de transporte $[67,70]$.

\section{Manganeso}

Los resultados representan los primeros reportes de este elemento en los sedimentos y en los tejidos de peces de la Laguna de Castillero. Las concentraciones de manganeso (TABLA III; FIG. 4) oscilaron entre 23, $95 \mu \mathrm{g} / \mathrm{g}$ y $197,97 \mu \mathrm{g} / \mathrm{g}$ 
Concentraciones de metales en sedimentos y tejidos musculares de algunos peces de la Laguna de Castillero / Márquez, A. y col.

TABLA VI

CONCENTRACIONES DE METALES FE, Mn, Pb, Zn y Co $(\mu \mathrm{g} / \mathrm{g})$ EN TEJIDOS MUSCULARES DE PECES DE LA LAGUNA DE CASTILLERO, VENEZUELA./ METAL CONCENTRATIONS OF Fe, Mn, Pb, Zn AND Co ( $\mu \mathrm{g} / \mathrm{g}$ ) IN MUSCULAR TISSUES OF SOME FISHES FROM THE CASTILLERO LAGOON, VENEZUELA.

\begin{tabular}{|c|c|c|c|c|c|c|}
\hline & Talla $(\mathrm{cm})$ & $\mathrm{Pb}$ & $\mathrm{Mn}$ & $\mathrm{Fe}$ & $\mathrm{Zn}$ & Co \\
\hline $\begin{array}{l}\text { Plasgiosium squamossimos } \\
\text { (Curvinata) }\end{array}$ & $10-12$ & $0,38 \pm 0,01$ & $4,16 \pm 0,03$ & $31,26 \pm 0,06$ & $32,23 \pm 0,01$ & nd \\
\hline $\begin{array}{l}\text { Pigocentrus cariba } \\
\text { (Caribe) }\end{array}$ & $7-9$ & $0,34 \pm 0,01$ & $3,91 \pm 0,03$ & $64,35 \pm 0,06$ & $19,09 \pm 0,01$ & nd \\
\hline $\begin{array}{l}\text { Pheudoplastyloma fasciatum } \\
\text { (Bagre rayado) }\end{array}$ & $18-22$ & $0,47 \pm 0,03$ & $3,50 \pm 0,05$ & $68,36 \pm 0,05$ & $27,07 \pm 0,01$ & nd \\
\hline $\begin{array}{l}\text { Hypostomus spp. } \\
\text { (Guaraguara) }\end{array}$ & $7-9$ & $0,39 \pm 0,05$ & $2,02 \pm 0,05$ & $28,80 \pm 0,04$ & $28,89 \pm 0,01$ & nd \\
\hline
\end{tabular}

(nd $=$ no detectado).

con un promedio de $132,27 \mu \mathrm{g} / \mathrm{g}$. Se apreciaron variaciones significativas, específicamente entre las concentraciones de las estaciones ubicadas en la parte este y oeste de la laguna. Los menores valores $(23,95 \mu \mathrm{g} / \mathrm{g}$ y $70,42 \mu \mathrm{g} / \mathrm{g})$ correspondientes a las estaciones 6 y 7 , respectivamente, fueron detectados en el extremo oriental, la cual representa la zona más alejada de interconexión de las lagunas, La Tejita- Castillero. En la Laguna Castillero investigaciones sobre los niveles de manganeso han sido efectuados solo en el agua y en algunos organismos vegetales como E. crassipes [44, 45]. En los estudios señalados por estos autores, se determinaron concentraciones de manganeso entre $1716 \mu \mathrm{g} / \mathrm{g}$ - 1916,67 $\mu \mathrm{g} / \mathrm{g}$ para $E$. crassipes y de 0,62 mg/l y $23 \mathrm{mg} / \mathrm{l}$ para el agua.

En otros ecosistemas venezolanos, como la Laguna de Las Marites, se han determinado valores de $94,57 \mu \mathrm{g} / \mathrm{g}$ de manganeso [52]. Similarmente, para la Bahía de Pozuelos en el estado Anzoátegui y áreas adyacentes, se han reportado niveles entre $8 \mu \mathrm{g} / \mathrm{g}$ y $70 \mu \mathrm{g} / \mathrm{g}[20,58)$. Para los sedimentos de la Laguna de Chacopata por otra parte, valores de $24,84 \mu \mathrm{g} / \mathrm{g}$ han sido señalados [18], al igual que en Río Chico y Güiria (Venezuela), donde se han indicado niveles de $78,2 \mu \mathrm{g} / \mathrm{g}$ y $18 \mu \mathrm{g} / \mathrm{g}$ [1]. En lagunas litorales ubicadas en el estado Anzoátegui, como el caso de la Laguna de Píritu y Unare se han reportado concentraciones de manganeso entre $47,12 \mu \mathrm{g} / \mathrm{g}$ y $1685,50 \mu \mathrm{g} / \mathrm{g}$ y entre $276,80 \mu \mathrm{g} / \mathrm{g}-971 \mu \mathrm{g} / \mathrm{g}$, respectivamente [19, 30]. De los ecosistemas antes señalados solo las lagunas de Píritu y Unare presentan concentraciones superiores a la de Castillero.

En los peces, las concentraciones de manganeso determinadas oscilaron entre $2,02 \mu \mathrm{g} / \mathrm{g}$ para Hypostomus spp y 4,16 $\mu \mathrm{g} / \mathrm{g}$ para $P$. squamossimos. Valores intermedios de $3,50 \mu \mathrm{g} / \mathrm{g}$ y $3,91 \mu \mathrm{g} / \mathrm{g}$ fueron detectados para $P$. fasciatum y $P$. cariba, respectivamente. El manganeso es un metal esencial en el metabolismo enzimático de muchas especies [67]. En los sistemas acuáticos presenta una gran reactividad, especialmente en sistemas estuarinos, y la alta capacidad de adsorción de metales, contribuyendo significativamente a la caracterización y el comportamiento de estos elementos en los estuarios y lagunas [34].

\section{Zinc}

Los resultados representan los primeros reportes de este elemento en los sedimentos y en los tejidos de peces de la Laguna de Castillero. Las concentraciones de zinc oscilaron entre $686,60 \mu \mathrm{g} / \mathrm{g}$ y $12,41 \mu \mathrm{g} / \mathrm{g}$ con promedio de $253,04 \mu \mathrm{g} / \mathrm{g}$ (TABLA II; FIG. 4). Los valores elevados fueron detectados en la zona sur-occidental de la laguna, cerca de unión con la Laguna Tejita, donde las concentraciones fluctúan entre $166,87 \mu \mathrm{g} / \mathrm{g}$ y $686,60 \mu \mathrm{g} / \mathrm{g}$. Los valores de zinc determinados en los sedimentos de la zona estudiada, son superiores al valor $110 \mu \mathrm{g} / \mathrm{g}$ los indicado para sedimentos no contaminados [51].

La correlación de los metales con el hierro debe ser el comportamiento esperado en condiciones naturales ya que el hierro es un elemento definitorio de las características de los sedimentos, razón por la cual la relación del hierro con cualquier otro metal formará una tendencia lineal, lo contrario podría ser significativo de una contaminación de tipo antrópico $[49,50]$. En esta investigación, no se observó correlación entre el zinc y el hierro (TABLA V), sugiriendo una posible intrusión de zinc en la laguna por fuentes no naturales. Las descargas provenientes de las aguas residuales y de la empresa ELEORIENTE durante los años 1988-1991, probablemente estén asociadas a la entrada del zinc en la Laguna de Castillero. El zinc es un metal que junto al hierro y el cobalto es requerido por el organismo, sin embargo, un aumento en las concentraciones lo hace tóxico para los organismos acuáticos.

En los peces de la Laguna de Castillero a su vez, las concentraciones de zinc oscilaron entre $19,09 \mu \mathrm{g} / \mathrm{g}$ para $P$. cariba y $32,23 \mu \mathrm{g} / \mathrm{g}$ para $P$. squamossimos. Valores intermedios de $27,07 \mu \mathrm{g} / \mathrm{g}$ y $28,89 \mu \mathrm{g} / \mathrm{g}$ fueron detectados para $P$. fasciatum y Hypostomus spp, respectivamente. Los niveles de zinc determinados en los tejidos de los peces estudiados, fueron altos e inclusive en algunos casos mayores a los del hierro, tal como se evidencia para $P$. squamossimos y Hypostomus. spp (TABLA III). En la Laguna de Castillero se han reportado concentraciones de zinc de 0,01 mg/l en el agua, durante de los meses de aguas bajas, febrero-julio, valores que son bajos y 
que hacen suponer que, en el sedimento, la acumulación no es originada principalmente por los niveles naturales del agua de la laguna, sino que existe o existió una fuente de entrada antrópica que ha originado acumulación del metal en los sedimentos [45].

En otros ecosistemas de Venezuela, como la cuenca Tuy-Cariaco, se han determinado promedios de $57,18 \mu \mathrm{g} / \mathrm{g}$ en los sedimentos superficiales [19], valores de $34,01 \mu \mathrm{g} / \mathrm{g}$ para los sedimentos de la Laguna de Las Marites [52] y de 456,6 $\mu \mathrm{g} / \mathrm{g}$ en los de la Bahía de Bergantín [20]. Para los sedimentos de la Laguna de Chacopata, niveles de $14,90 \mu \mathrm{g} / \mathrm{g}$ han sido reportados [18], al igual que promedios de $300 \mu \mathrm{g} / \mathrm{g}$ en los sedimentos superficiales de la Bahía de Pozuelos [58], indicándose en este último caso, existencia de contaminación por zinc. Concentraciones de $127,49 \mu \mathrm{g} / \mathrm{g}$ y $116,69 \mu \mathrm{g} / \mathrm{g}$, también han sido señaladas para las lagunas de Unare y Píritu respectivamente $[17,30]$. Todos los ecosistemas antes señalados, a pesar de encontrarse en zonas costeras que generalmente presentan un mayor impacto ecológico, presentan niveles inferiores a la Laguna de Castillero. Estas observaciones ponen en evidencia el progresivo impacto ecológico que se ha venido suscitando en el ecosistema de la Laguna Castillero.

El zinc vertido al medio ambiente por las fuentes antropogénicas supera al zinc vertido por las fuentes naturales [61, 63]. Las aguas servidas representan una fuente importante de metales en donde el zinc es uno de los elementos más abundantes con concentraciones que llegan a alcanzar en algunos casos concentraciones de $250 \mathrm{mg} / \mathrm{l}$ [61]. Las concentraciones de zinc en los sedimentos son inferiores a $100 \mu \mathrm{g} / \mathrm{g}$, sin embargo, los valores correspondientes a zonas contaminadas, como las que reciben desagües ácidos provenientes de la industria minera y otros efluentes generados en el procesamiento de metales y en la producción de manufacturas, así como, también aguas servidas provenientes de los hogares incluyen concentraciones que van desde $0,650 \mathrm{mg} / \mathrm{la} 1,187 \mathrm{mg} / \mathrm{l}$ de $\mathrm{Zn}[7,11,61]$.

En otros ecosistemas se han determinado concentraciones de zinc que oscilan entre < $100 \mu \mathrm{g} / \mathrm{g}$ y $1.320 \mu \mathrm{g} / \mathrm{g}$, tal es el caso de la península del lago Kola en Rusia [15]. De igual manera, niveles entre $200 \mu \mathrm{g} / \mathrm{g}$ y $5.000 \mu \mathrm{g} / \mathrm{g}$ han sido señalados para los sistemas estuarinos de los ríos Tinto y Odiel [38] y valores de $3.000 \mu \mathrm{g} / \mathrm{g}$ para la Caleta de Restongeut al sudoeste de Inglaterra [7].

Las evidencias sobre la biodisponibilidad del zinc en sedimentos han sido documentadas en investigaciones con plantas acuáticas vasculares adheridas al sedimento e invertebrados que se alimentan de los sedimentos, tal es el caso de los moluscos y plantas recogidos en el río Ebro [59]. Las concentraciones de $\mathrm{Zn}$ determinadas en estos organismos ha puesto en evidencia el peligro que genera la acumulación de este metal en los sedimentos [59]. Otros investigadores, han indicado que los organismos relacionados con el sedimento presentan concentraciones de zinc más elevada que los organismos que habitan en la capa acuosa [6, 61]. En el río la Plata (Argentina) se han reportado bioacumulación del zinc en peces y organismos bentónicos relacionados con los sedimentos contaminados, apreciándose niveles que oscilan entre 80 y $109 \mu \mathrm{g} / \mathrm{g}$ en peces y de 340 a $450 \mu \mathrm{g} / \mathrm{g}$ en los tejidos pancreáticos de los caracoles [66].

\section{Plomo}

Los resultados representan los primeros reportes de este elemento en los sedimentos y en los tejidos de peces de la Laguna de Castillero. La concentración promedio de plomo para la Laguna de Castillero fue de $17,02 \mu \mathrm{g} / \mathrm{g}$, con valores que oscilaron entre $7,91 \mu \mathrm{g} / \mathrm{g}$ y $22,84 \mu \mathrm{g} / \mathrm{g}$ respectivamente (TABLA I; FIG. 5). Se apreciaron variaciones estadísticas significativas en las concentraciones de los metales en el sedimento (TABLA IV). Los valores máximos de plomo, los cuales variaron entre $20 \mu \mathrm{g} / \mathrm{g}$ y $22 \mu \mathrm{g} / \mathrm{g}$ fueron determinados en la parte centro occidental y sur de la laguna, observándose al mismo tiempo, una buena correlación lineal positiva y altamente significativa con las concentraciones de hierro y manganeso (TABLA IV). Esta observación corrobora lo señalado por otros investigadores, quienes indican que, el plomo se encuentra asociado en adsorción con los óxidos de hierro y manganeso $[30,54]$. En la Laguna de Castillero han sido reportados niveles de plomo entre $0,016 \mathrm{mg} / \mathrm{l}$ y $0,027 \mathrm{mg} / \mathrm{l}$ en el agua, observándose que las concentraciones máximas se alcanzan entre los meses de octubre y diciembre [44, 45].

En los peces de la Laguna de Castillero, las concentraciones de plomo por su parte, oscilaron entre $0,34 \mu \mathrm{g} / \mathrm{g}$ para $P$. cariba y $0,47 \mu \mathrm{g} / \mathrm{g}$ en $P$. fasciatum. Valores intermedios de $0,38 \mu \mathrm{g} / \mathrm{g}$ y $0,39 \mu \mathrm{g} / \mathrm{g}$ fueron determinados para $P$. squamossimos y Hypostomus spp., respectivamente. La presencia de plomo en el sedimento y en los tejidos de los peces de la Laguna de Castillero ponen en evidencia un potencial peligro para las especies ícticas e igualmente para la población de Caicara del Orinoco, la cual sustenta en parte su economía en la explotación de los recursos pesqueros de la laguna y del canal principal del Orinoco Medio.

En otros ecosistemas venezolanos se han indicado promedios de plomo que alcanzan 11, $7 \mu \mathrm{g} / \mathrm{g}$ en los sedimentos superficiales de la Bahía de Pozuelos [58], niveles de 8,66 $\mu \mathrm{g} / \mathrm{g}$ para los de la Laguna de Chacopata [20] y valores de $29 \mu \mathrm{g} / \mathrm{g}$ y 16,5 $\mu \mathrm{g} / \mathrm{g}$ para las lagunas de Unare y Píritu, respectivamente, en el estado Anzoátegui [17, 30]. En otras lagunas latinoamericanas como las Lagunas de Tampamachoco, Mandinga y Alvarado en México, se han indicado valores de $3,94 \mu \mathrm{g} / \mathrm{g}$ y $20,15 \mu \mathrm{g} / \mathrm{g}$, respectivamente, para sus sedimentos $[46,47]$. De igual manera, niveles de $158,7 \mu \mathrm{g} / \mathrm{g}$ han sido determinados en la Laguna de las llusiones (Tabasco, México), asociándose estos valores a la introducción continua de aguas residuales y a las emisiones atmosféricas provenientes de las áreas urbanas e industriales [69].

Hay muchas discrepancias en cuanto a los niveles considerados como contaminantes para el plomo, valores de 4-12 $\mu \mathrm{g} / \mathrm{g}$ y $5 \mu \mathrm{g} / \mathrm{g}$ han sido señalados para sedimentos no contami- 
Concentraciones de metales en sedimentos y tejidos musculares de algunos peces de la Laguna de Castillero / Márquez, A. y col.

nados [35, 51]. Estos valores son inferiores a los determinados en la Laguna de Castillero en la presente investigación. Sin embargo, otros autores señalan concentraciones entre 10 a 50 $\mu \mathrm{g} / \mathrm{g}$ para sedimentos no contaminados [7, 11, 29, 53].

Si se toma en consideración las sugerencias señaladas $[35,51]$ se puede concluir que, las concentraciones determinadas en esta investigación ponen en evidencia impactos ecológicos para el ecosistema bajo estudio, ya que los valores son altos con respecto a los niveles señalados por estos autores. Las concentraciones de plomo determinadas en esta investigación, han de tenerse en consideración, puesto que este elemento puede alterar el metabolismo de los organismos vivos debido a su gran capacidad para adsorberse en la superficie de algunos organismos acuáticos $[43,60]$.

Los niveles de plomo correspondiente a zonas contaminadas, incluyen valores que pueden alcanzar $2.700 \mu \mathrm{g} / \mathrm{g}$. tal como ocurre en el estuario de Gannel al sudoeste de Inglaterra [7] y en los ríos Tinto y Odiel $(1.000 \mu \mathrm{g} / \mathrm{g}$ a $2.000 \mu \mathrm{g} / \mathrm{g})$, respectivamente [61]. Estos valores han sido asociados a las actividades mineras, desagües urbanos y descargas de aguas servidas. En el río la Plata (Argentina) se han determinados niveles de plomo entre 30 y $70 \mu \mathrm{g} / \mathrm{g}$ como producto de las actividades antropogénicas [66].

En el medio ambiente, el plomo se encuentra en múltiples formas químicas, aunque la mayor parte se encuentra como especies inorgánicas. Las actividades humanas son la fuente principal de la contaminación por plomo debido a la combustión del petróleo y la gasolina, las cuales contribuyen con un $5 \%$ de todas las emisiones antropogénicas y es el principal componente del ciclo global de plomo [17]. Además de aparecer en forma inorgánica, hay evidencias de que en ausencia del plomo orgánico, el inorgánico se puede alquilar, química o biológicamente, para producir compuestos de plomo mono-di y trialquilicos que son las formas las más tóxicas [42]. El gran peligro de la presencia de plomo en los sedimentos de la Laguna de Castillero radica en que se han señalado evidencias de la biodisponibilidad del plomo para los organismos que se alimentan del sedimento [7].

\section{Cobalto}

Los resultados de esta investigación representan los primeros reportes para el ecosistema de la Laguna de Castillero. Las concentraciones de cobalto en el sedimento variaron entre $1,14 \mu \mathrm{g} / \mathrm{g}$ y $6,92 \mu \mathrm{g} / \mathrm{g}$ (FIG.5) con promedio de 4,65 $\mu \mathrm{g} / \mathrm{g}$, no detectándose en el tejido de los peces. Las máximas concentraciones se distribuyeron en la zona occidental de la laguna, en la zona de influencia de la Laguna Tejita (estaciones 2, 3, $4,5)$, apreciándose por otra parte variaciones significativas entre todas las estaciones (TABLA IV). El cobalto presentó buena correlación lineal de tipo positiva con el hierro y manganeso sugiriendo orígenes similares. Los valores determinados son comparables a los niveles $<9 \mu \mathrm{g} / \mathrm{g}$ reportados para otros ecosistemas no venezolanos, como la cuenca de Matanzas-Riachuelo en Argentina [61]. Para el arroyo las Toscas en la Pro- vincia de Santa Fe, Argentina, concentraciones $<5 \mu \mathrm{g} / \mathrm{g}$ de cobalto han sido reportadas [27], valores que son comparables a los determinados en la Laguna de Castillero. El cobalto es un metal biológicamente importante, aunque sólo pocas métaloproteínas del cobalto son conocidas [26]. Igualmente es escaso el conocimiento sobre el comportamiento biogeoquímico del cobalto en los sistemas acuáticos [16], sin embargo, hay fuertes evidencias que señalan que el metal tiende a formar complejos con ligandos orgánicos en los ríos y estuarios [74], así como en los mares y océanos, en donde llega ser un limitante del desarrollo del fitoplancton [16, 65]. Esta última observación debido a que, cuando existe limitación de zinc, el cobalto actúa sustituyéndolo en la enzima anhydrasa carbónica $[41,72]$.

Sánchez $[54,55]$, indica que las concentraciones de metales pesados considerados como niveles normales para el ecosistema del Orinoco, se encuentran aguas arriba de las ciudades de Ciudad Bolívar y Ciudad Guayana en el estado Bolívar, Venezuela, sin embargo, los resultados obtenidos de esta investigación contrastan con estas observaciones ya que se evidencia contaminación por zinc y acumulación de plomo en los sedimentos de la Laguna de Castillero, laguna que se encuentra aguas arriba de estas dos ciudades.

\section{CONCLUSIONES}

Todos los metales, con excepción del zinc parecieran tener orígenes similares debido a la correlación que presentan con las concentraciones de hierro. Tal vez este origen provenga de los oxi-hidróxidos de hierro y manganeso. Al mismo tiempo estos elementos están asociados en su mayoría a la fracción del grano fino del sedimento, especialmente a los lodos.

Se evidencia contaminación por zinc en los sedimentos superficiales de la Laguna de Castillero, probablemente asociada a la descarga de las aguas residuales de la comunidad y de la empresa ELEORIENTE durante los años 1988 a 1991. Esto se evidencia igualmente por los altos valores detectados, no solo para el zinc, sino para todos los metales en la interconexión de la Laguna de Castillero y La Tejita.

Posibles cambios en las condiciones fisicoquímicas, en especial en el potencial redox del sedimento podrían generar condiciones para la liberación de los metales hacia el agua causando bioacumulación de metales como el zinc y el plomo. Por otra parte las evidencias de la biodisponibilidad del plomo y el zinc, documentadas en otras investigaciones, podrían crear un potencial problema para el ecosistema de la Laguna de Castillero.

En el caso de los niveles de metales en peces, las altas concentraciones de zinc y la presencia de plomo, podrían estar reflejando lo expuesto en la conclusión número tres, corroborando la evidencia un potencial peligro para las especies ícticas de la laguna y para la población que explota la laguna como fuente de sustento económico. 
Siendo los primeros reportes de metales como $\mathrm{Mn}, \mathrm{Zn}$, $\mathrm{Pb}$ y Co para el sedimento y de $\mathrm{Fe}, \mathrm{Mn}, \mathrm{Zn}, \mathrm{Pb}$ y Co, estas concentraciones podrían servir de referencia para posteriores estudios a realizarse en el ecosistema de la Laguna de Castillero.

\section{AGRADECIMIENTO}

Los autores agradecen a FUNDACITE GUAYANA, la colaboración prestada para la realización de esta investigación, a través del financiamiento del proyecto: Proyecto Orinoco: Evaluación de las concentraciones de metales pesados en aguas superficiales y sedimentos de fondo en un sector del Medio Orinoco, Venezuela (Proyecto número: 000606).

\section{REFERENCIAS BIBLIOGRÁFICAS}

[1] ACOSTA, V.; LODEIROS, C.; SENIOR, W.; MARTÍNEZ, $G$. Niveles de metales pesados en sedimentos superficiales en tres zonas litorales de Venezuela. Intercien. 27 (12): 686-690. 2002.

[2] AlONGI, D.; BOYLE, S.; TIRENDI, F.; PAYN, C. Composition and behavior of trace metals in post-oxic sediments of the Gulf of Papua, Papua New Guinea. Estuar. Coastal and Shelf. Sci. 42: 197-211. 1996.

[3] ANDERSEN, $\varnothing$. Accumulation of waterborn iron and expression of ferreting and transferring in early developmental stages of brown trout Salmo trutta. Fish. Physiolog. and Biochem. 16 (3): 223-231. 1997.

[4] ANDRADE, J.; MARTINS, C.; CHARZEDDINE, L.; MARTíNEZ, G, Metales pesados en el poliqueto tubícula Americomphis magna (Andrew, 1981) (Annelida: Polichaeta). Saber. 9 (1):12-16. 1997.

[5] BEST, R. The aquatic mammals and reptiles of the Amazon. In: The Amazon: Limnology and landscape ecology of a mighty tropical rivers and its basin. $\mathrm{H}$. Sioli (Ed). Dr. W. Junk Publishers, Dordrecht. 371-412 pp. 1984.

[6] BIDDINGER, G.; GLOSS, S. The importance of tropic transfer in the bioaccumulation of chemical contaminants in aquatic ecosystems. Resid. Rev. 91: 103-145. 1984.

[7] BRYAN, G.; LANGSTON, W. Bioavility, accumulation and effects of heavy metals in sediments with special reference to the united Kingdom Estuaries: a review. Envir. Poll. 76: 89-131. 1992.

[8] CACADOR, A.; VALE, C.; CATARINO, F. Accumulation of $\mathrm{Zn}, \mathrm{Pb}, \mathrm{Cu}, \mathrm{Cr}$, and $\mathrm{Ni}$ in sediments between roots of the Tagus Estuary Salt Marshes, Portugal. Estuar. Coastal and Shelf. Sci. 42: 393-403. 1996.

[9] CLEMENTS, W.; RESS, D. Effects of heavy metals on prey abundance, feeding habitats and metal uptake of brown trout in the Arkansas River Colorado. Trans. Amer. Fish. Soc. 126: 774-785. 1997.
[10] COLONNELLO, G. Elementos fisiográficos y ecológicos de la cuenca del río Orinoco y sus rebalses. Intercien.15 (6): 476-485. 1990.

[11] CONCALVES, E.; BOAVENTURA, R.; MOUVET, C. Sediments and aquatic mosses as pollution indicators for heavy metals in the Ave river basin, Portugal. The Scie. of the Total Environm.114: 7-24. 1990.

[12] CORPORACIÓN VENEZOLANA DE GUAYANA-GERENCIA DE OBRAS SANITARIAS E HIDRÁULICAS, CAICARA DEL ORINOCO (CVG-GOSH). Informe sobre las descargas cloacales de la población de Caicara del Orinoco durante el período 1988-1996. Corporación Venezolana de Guayana-Gerencia de Obras sanitarias e Hidráulicas, Caicara del Orinoco.22 pp. 1997.

[13] DASKALAKIS, K.; CONNORS, T. Distribution of chemical concentration in US Coastal and estuarine sediment. Mar. Environm. Res. 40(4): 381-398. 1995.

[14] DASSENAKIS, M.; SCOULLOS, M.; GAITIS, A. Trace metals transport and behavior in the Mediterranean estuary of Acheloos River. Mar. Poll. Bull.34 (2): 103-111. 1997.

[15] DAUVALTER, V. Heavy metals in lake sediments of the Kola Peninsula, Russia. The Scie. of the Total Environm. 158: 51-61. 1994.

[16] ELLWOOD, M.; VAN DEN BERG, C. Determination of organic complexation of cobalt in seawater by cathodic stripping voltammetry. Mar. Chem. 75: 33-47. 2001.

[17] FERMíN, I. Estudio Geoquímico de la laguna de Unare, Estado Anzoátegui, Venezuela. Inst. Oceanogr. Univ. Oriente. Tesis de Grado. 106 pp. 2002.

[18] FUENTES, M. Condiciones geoquímicas de los sedimentos superficiales de la Laguna de Chacopata, Edo. Sucre, Venezuela. Inst. Oceanogr. Univ. Oriente. Tesis de Grado. 113 pp. 1998.

[19] GAMBOA, B.; BONILLA, J. Distribución de metales (Fe, $\mathrm{Mn}, \mathrm{Cu}, \mathrm{Zn}$ ) en sedimentos superficiales de la cuenca Tuy-Cariaco. Bol. Inst. Oceanogr. Univ. Oriente. 22 (1-2): 103-110. 1983.

[20] GAMBOA, B.; BONILLA, J.; CEDEÑO, G. Concentración de algunos metales pesados en sedimentos superficiales de la Bahía de Pozuelos y áreas adyacentes, Estado Anzoátegui. Venezuela. Bol. Inst. Oceanogr. Univ. Oriente. 25 (1-2): 233-240. 1986

[21] GERLACH, S. Metal pollution. In: Marine Pollution: Diagnosis and Therapy. Springer-Verlang. Berlín, Heidelberg, New York. 218 pp. 1981.

[22] GONZÁlEZ, A.; MÁRQUEZ, A.; CHUNG, K.S. Hierro y cobre en Plagioscion squamosissimus (Piscis: Sciaenidae) del río Orinoco, Venezuela. Rev. Biol. Trop. 48 (1): 207-213. 2000. 
Concentraciones de metales en sedimentos y tejidos musculares de algunos peces de la Laguna de Castillero / Márquez, A. y col.

[23] HAMILTON, S.; LEWIS, W. Physical characteristics of the fringing floodplain of the Orinoco River, Venezuela. Intercien. 15 (6): 491-499. 1990.

[24] HENRICHS, S. Early diagenesis of organic matter in marine sediments: progress and perplexity. Mar. Chem. 39 (1-3): 119-149. 1992.

[25] JUNK, E. Amazonian floodplains: Their ecology, present and potential use. Rev. Hydrobiol. Trop. 15:285-301. 1982.

[26] KOBAYASHI, M.; SHIMIZU, S. Cobalt proteins. Europ. J. of. Biochem. 261: 1-9. 1999.

[27] LABUNSKA, I.; BRIGDEN, K.; STRINGER, R.; JOHNSTON, P.; SANTILLO, D.; ASHTON, J. Identificación y trascendencia ambiental de contaminantes orgánicos y metales pesados asociados con la curtiembre Arlei S.A., Las Toscas, Provincia de Santa Fe, Argentina. Laboratorios de Investigación de Greenpeace, Departamento de Ciencias Biológicas, Universidad de Exeter Reino Unido. Diciembre de 2000. Nota Técnica. 15 pp. 2000.

[28] LEWIS, B.; LANDING, W. The investigation of dissolved and suspended particulate trace metals fractionation in the Black Sea. Mar. Chem. 40: 105-141. 1992.

[29] LICHENNG, Z.; KEZHUN, Z. Background values of trace elements in the source area of the Yangtze River. The Sci of the Total Environm. 125: 391-404. 1992.

[30] LÓPEZ, F. Estudio Geoquímico de La laguna de Píritu, Estado Anzoátegui, Venezuela. Inst. Oceanogr. Univ. Oriente. Tesis de Grado. 109 pp. 2002.

[31] LORING, D. Normalization of heavy metal data from estuarine and coastal sediments. ICES. J. Mar. Sci. 48: 101-116. 1991.

[32] MALCOLM, H.; BOYD, I.; OSBORN, D.; FRENCH, M.; FREESTONE, P. Trace metal in Antarctic furseal (Arctocephalus gazella) livers from Bird Island, South Georgia. Mar. Poll. Bull. 28: 375-380. 1994.

[33] MÁRQUEZ, A.; SENIOR, W.; MARTÍNEZ, G. Concentración y comportamiento de metales pesados en una zona estuarina de Venezuela. Intercien. 25: 284 -291. 2000.

[34] MOORE, J.; RAMAMMORTHY, S. Iron. In: Heavy Metals in Natural Waters. Moore and Ramamoorthy (Eds). New York. Springer-Verlag. 268 pp. 1984.

[35] MORRISON, R.; GANGAIYA, P, NAQASIMA, M.; NAIDU, N. Trace metal studies in the Great Astrolabe Lagoon, Fiji. Mar. Poll. Bull. 1566. 1-8. 1997.

[36] NELSON, C.; LAMOTHE, P. Heavy metals anomalies in the Tinto and Odiel river and estuary system, Spain. Estuar. Res. Fundat.16 (3A): 496-511. 1993.

[37] NOVOA, D. Diagnóstico socioeconómico de las pesquerías artesanales del río Orinoco. En: Los Recursos Pes- queros del Río Orinoco y su Explotación. Corporación Venezolana de Guayana, Editorial Arte, Caracas, Venezuela. 386 pp. 1982.

[38] OJASTI, J. Ecology of Capibara raising on inundated savannas of Venezuela. Trop. Ecol. Dev. 1980: 287-293. 1980.

[39] PAULSON, A.; SHARACK, B.; ZDANOWICZ, V. Trace metals in ribbed mussels from Arthur Kill, New York/New Jersey, USA. Mar. Poll. Bull. 46:139-152. 2003.

[40] PETTS, G.; FOSTER, I. Stream channel morphology and position. Rivers and Landscape. Edgar Arnold (Eds), London.274 pp. 1985.

[41] PRICE, N.; MOREL, F. Cadmium and cobalt substitution for zinc in a marine diatom. Nature 344: 658-660. 1990.

[42] RADOJEVIC, M.; HARRISON, P. Concentrations and pathways of organic lead compounds in the environment. The Sci. of the Total Environm. 59: 157-180. 1987.

[43] RAINBOW, P. The Significance of Trace Metal Concentration in Marine Invertebrates. In: Ecoxitology of Metals in Invertebrates. Lewis Publisher. Boca Raton. F.L. 3 -23pp. 1993.

[44] RODRÍGUEZ, J.; BETANCOURT, L. Estratificación morfológica de la Bora (Eichhornia crassipes (Mart.) Solms) y efecto de su cobertura en una laguna de inundación del Orinoco Medio. Mem. IV. Congreso. Interamericano del Medio Ambiente (CIMA 1997). Caracas. 1997. 121-127pp. 1998.

[45] RODRÍGUEZ, J.; BETANCOURT, L. Caracterización fisicoquímica de una laguna de inundación del tramo Orinoco Medio y su relación con la biomasa de la cobertura de Bora (Eichhornia crassipes (Mart.) Solms). Intercien. 24 (4): 243- 249. 1999.

[46] ROSALES, L.; CARRANZA, A.; ÁlVAREZ, U. Sedimentological and chemical studies in sediment from Alvarado Lagoon system, Veracruz, México. Univ. Nac. Auton. México. An. Inst. del Mar y Limnol.. 13 (3): 19-28. 1986.

[47] ROSAS, P.; BAEZ, A.; BELMONT, R. Oyster (Crassostrea virginica) as indicator of heavy metals pollution in some lagoons of the Gulf of México. Wat. Air. Soil. Poll. 20: 127-135. 1983.

[48] ROUX, L.; LE ROUX, S.; APPRIOU, P. Behavior and speciation of metallic species $\mathrm{Cu}, \mathrm{Cd}, \mathrm{Mn}$ and Fe during estuarine mixing. Mar. Poll. Bull. 36 (1): 56-64. 1998.

[49] RUBIO, B.; NOMBELA, M.; VILAS, F. Geochemistry of majors and trace elements in sediment of the Ria de Vigo (NW Spain): an assessment of metal pollution. Mar. Poll. Bull. 40 (11): 968-980. 2000.

[50] RUBIO, B.; NOMBELA, M.; VILAS, F.; ALEJO, I.; GARCÍA-GIL, S.; GARCÍA-GIL, E.; PAZOS, O. Distribución y enriquecimiento de metales pesados en sedimentos ac- 
Revista Científica, FCV-LUZ / Vol. XVIII, № 2, 121 - 133, 2008

tuales de la parte interna de la Ría de Pontevedra. Thalassas. 11: 35-45. 1995.

[51] SADIQ, M. Heavy metals. In: Toxic metal chemistry in marine environments. Marcel Dekker, Inc., New York, 390 pp. 1992.

[52] SALAZAR, J.; BONILLA, J.; GAMBOA, B. Metales pesados y materia orgánica en los sedimentos superficiales de la Laguna Las Marites. Bol. Inst. Oceanogr. Univ. Oriente. 25 (1-2): 137-154. 1986.

[53] SALOMONS, W; FORSNER, U. Speciation of heavy metals in soils and groundwater and implications for their natural and provoked mobility. Metals in the Hydrocycle. ISBN Springer-Verlag, Berlin, Heidelberg, New York. 449pp. 1984.

[54] SÁNCHEZ, L.; VÁSQUEZ, E. Notas sobre las macro fiítas acuáticas en la sección baja del río Orinoco. Mem. Soc. Cien. Nat. La Salle.46 (125-26):107-125 1986.

[55] SÁNCHEZ, M. La calidad de las aguas del río Orinoco. En: El Río Orinoco omo Ecosistema. EDELCA. CCAVN. Universidad Simón Bolívar. 430 pp. 1990.

[56] SCOTT, M.; NEUMANN, R. Seasonal variations in concentrations of mercury in axial muscle tissues of largemouth bass. Norhj. Amer. Jr. Fish. Manag. 19: 89-96. 1999.

[57] SOKAL, R; ROHLF, J. The principles and practice statistics in biological research. In: Biometry W. H. Freeman and Company. USA.776 pp. 1969

[58] SENIOR, W.; CASTAÑEDA, J. Evaluación ambiental de las bahías de Bergantín, Pozuelos y Barcelona, ubicadas en las costas del Edo. Anzoátegui. Informe final. PDVSA. 133 pp. 1997.

[59] SHCUMATCHER, M.; DOMINGO, J.; LLOBET, J.; CORBELLA, J. Variations of heavy metals in water, sediments and biota from the Delta of the Ebro River, Spain. J. Envir. Sci. and Health. 30(6):1361-1372. 1995.

[60] SONG, Y.; MÜLLER, G. Biogeochemical cycling of nutrients and trace metals in anoxic freshwater sediments of the Neckar River. Germ. Mar. Freshwater. Res. 46: 237-43. 1995.

[61] STEPHENSON, A.; LABUNSKA, I.; STRINGER, R.; SANTILLO, D. Identificación y trascendencia ambiental de los contaminantes orgánicos y de los metales pesados hallados en las muestras de agua y sedimentos tomadas en la Cuenca Matanzas-Riachuelo, Argentina. Lab. Invest. De Greenpeace, Univ, Exeter, Reino Unido. Informe técnico final: 47 pp. 1998.

[62] TAM, N.; WONG, Y. Spatial and temporal variations of heavy metal contamination in sediments of a mangrove swamp in Hong Kong. Mar. Poll. Bull. 31 (4-12): 254261. 1995
[63] US PUBLIC HEALTH SERVICE (USPHS). Toxicological Profile for Zinc. Agency for Toxic Substances and Disease Registry. U.S. Public Health Service. Atlanta GA: ATSDR (CD-ROM). 1997.

[64] VÁSQUEZ, E.; WILBERT, W. The Orinoco: Physical, Biological and Cultural Diversity of Major Tropical Alluvial River. IN: Callow, P \& Geffrey, P. (Eds). The Rivers Hand book Vol. 1. Blackwell Scientific Publications. Oxford. 510 pp. 1992.

[65] VEGA, M.; VAN DEN BERG, C. Determination of cobalt in seawater by catalytic adsorptive cathodic stripping voltammetry. Anal. Chem. 69: 874-881. 1997.

[66] VERRENGIA-GUERRERO, N.; KARSTERN, E. Levels of heavy metals in biota from the La Plata River. Environm. Toxic. And Water Qual. 8: 335-344. 1993.

[67] VIARENGO, A. Biochemical effects of trace metals. Mar. Poll. Bull. 16 (4): 153-158. 1985.

[68] VILLAESCUSA-CELAYA, J.; GUTIÉRREZ, E.; FLORES, G. Metales pesados en fracciones geoquímicas de sedimentos de la región fronteriza de Baja California, México, y California, EUA. Sci. Mar. 23(1): 43-70. 1997.

[69] VILLANUEVA, F.S.; PÁEZ-OSUNA, F. Niveles de metales en el Golfo de México: agua, sedimentos y organismos. In: Golfo de México, Contaminación e Impacto Ambiental: Diagnóstico, y Tendencias. Botello, A; L, Rojas-Galaviz; J. Benítez y D, Zárate-Lomelí (Eds). Universidad Autónoma de Campeche. México. 666 pp. 1996.

[70] WELLS, M.; MAYER, L. Variations in the chemical lability of iron in estuarine coastal and shelf waters and its implication for phytoplankton. Mar. Chem. 32: 195-210. 1991.

[71] WOOD, C.; VAN VLEET, E. Cooper, cadmium and zinc in the liver, kidney and muscle tissues of bottlenose dolphins (Tursiops truncates) stranded in Florida. Mar. Poll. Bull. 32 (12): 886-889. 1996.

[72] YEE, D.; MOREL, F.M. In vivo substitution of zinc by cobalt in carbonic anhydrase of a marine diatom. Limnol. and Oceanogr. 41: 573-577. 1996.

[73] ZDANOWICZ, V.; FINNERAN, T.; KOTHE, R. Digestion of fish tissue and atomic absorption analysis of trace elements. In: Lauenstein, G., Cantillo, A. (Eds.). Sampling and Analytical Methods of the National Status and Trends Program: National Benthic Surveillance and Mussel Watch Program 1984-1992. NOAA Technical Memorandum NOS ORCA 71. National Oceanic and Atmospheric Administration, Silver Spring, MD. 31-51 pp. 1993.

[74] ZHANG, H.; VAN DEN BERG, C.; WOLLAST, R. The determination of interactions of cobalt II with organic compounds in seawater using cathodic stripping voltammetry. Mar Chem. 28: 285-300. 1990. 